DOI: https://doi.org/10.30749/2594-8261.v4n3p71-92

\title{
ANÁLISE DO DESEMPENHO DA EDUCAÇÃO BRASILEIRA BASEADA NOS INDICADORES OFICIAIS PISA E IDEB
}

\section{ANALYSIS OF THE PERFORMANCE OF BRAZILIAN EDUCATION BASED ON OFFICIAL PISA AND IDEB INDICATORS}

\author{
Cristina Nunes Rocha * \\ Ana Maria Pires Novaes * \\ Kátia Eliane Santos Avelar ${ }^{\star \star \star}$
}

Resumo: O Pisa é um indicador de desempenho da educação básica internacional que o aprendizado de alunos de vários países. O Ideb é um indicador de desempenho escolar nacional, aplicado pelo INEP. Por meio do ldeb é possível mensurar se as metas do Plano Nacional de Educação (PNE) estão sendo alcançadas, pois seus resultados servem como base para o planejamento e projeção de novas metas. $O$ objetivo deste estudo foi confrontar as metas projetadas pelo PNE com os resultados do Pisa e do Ideb, com o propósito de entender a situação atual em que se encontra a educação básica no Brasil. O estudo utilizou como metodologia a pesquisa bibliográfica e documental e análise descritiva dos dados. Inicialmente, o estudo abordou as características do Brasil que influenciam na educação, como, fatores históricos, tamanho da população, taxa de analfabetismo, economia e desigualdade na distribuição de renda. O período de análise compreendeu os resultados do Ideb de 2007 a 2017 e os resultados do Pisa 2015 e 2018. O estudo revelou que o Brasil obteve avanço na universalização do ensino e resultados positivos na educação infantil. Porém, os anos finais do ensino fundamental e ensino médio têm apresentado baixos índices educacionais no Pisa e Ideb e não alcançaram as metas projetadas. $O$ PNE tem o desafio de elaborar ações que promovam uma educação inclusiva e com equidade, considerando as desigualdades no ensino, que são históricas no país.

Palavras-chave: Ensino. Aprendizagem. Desempenho da Educação. Educação Básica.

\begin{abstract}
Pisa is a performance indicator of international basic education that the learning of students from several countries. Ideb is a national school performance indicator, applied by INEP. Through Ideb, it is possible to measure whether the goals of the National Education Plan (PNE) are being achieved, as their results serve as a basis for planning and projecting new goals. The aim of this study was to compare the goals projected by the PNE with the results of Pisa and Ideb, with the purpose of understanding the current situation in which basic education is found in Brazil. The study used bibliographic and documentary research and descriptive data analysis as methodology. Initially, the study addressed the characteristics of Brazil that influence education, such as historical factors, population size, illiteracy rate, economy and

\footnotetext{
* Mestranda pelo Programa de Pós-Graduação em Desenvolvimento Local do Centro Universitário Augusto Motta, UNISUAM. E-mail: cristinanunes1804@gmail.com

** Doutora em Letras pela Universidade Federal Fluminense, UFF. Docente da Fundação de Apoio à Escola Técnica - FAETEC e Pesquisadora em Educação Básica e Ensino-Aprendizagem. E-mail: profananovaes@hotmail.com

**** Doutora em Ciências pela Universidade Federal do Rio de Janeiro, UFRJ. Docente e Pesquisadora do Programa de Pós-Graduação em Desenvolvimento Local no Centro Universitário Augusto Motta, UNISUAM. E-mail: katia.avelar@gmail.com
} 
inequality in income distribution. The analysis period included the results of the Ideb from 2007 to 2017 and the results of the Pisa 2015 and 2018. The study revealed that Brazil has made progress in the universalization of teaching and positive results in early childhood education. However, the final years of primary and secondary education have shown low educational levels in Pisa and Ideb and have not achieved the projected goals. The PNE has the challenge of developing actions that promote an inclusive and equitable education, considering the inequalities in education, which are historical in the country.

Keywords: Teaching. Learning. Education Performance. Basic education. 


\section{INTRODUÇÃO}

A elaboração deste estudo foi inspirada na agenda 2030. Ela é um guia com objetivos e metas e seu intuito é incentivar o desenvolvimento sustentável como caminho para melhorar a qualidade de vida em todas as esferas da sociedade. A iniciativa dessa agenda global e seus preceitos para a educação inclusiva impulsionam os países a desenvolverem melhores políticas no âmbito educacional, podendo aprimorar a qualidade do ensino por todo o mundo, e, nesse cenário, destaca-se o papel fundamental dos educadores como agentes para a promoção de uma educação libertadora (AKKARI, 2017).

As desigualdades no ensino são históricas e marcam a trajetória da educação brasileira, com reflexos no desenvolvimento de políticas públicas e sua equidade. Segundo o Ministério da Educação (MEC), esse motivo constitui-se como um dos maiores desafios ao elaborar as metas para o Plano Nacional de Educação (PNE). Esse plano define o caminho a ser seguido para atingir os objetivos da agenda 2030 e melhorar a qualidade da educação, assim explica o Relatório Técnico do IDEB (INSTITUTO NACIONAL DE ESTUDOS E PESQUISAS EDUCACIONAIS ANÍSIO TEIXEIRA, [2017]).

Na perspectiva de avaliar a qualidade do ensino e medir a aprendizagem dos alunos em competências e habilidades essenciais, como português e matemática, utilizam-se como ferramentas, os indicadores de desempenho da educação básica, como o PISA (indicador internacional) e IDEB (indicador nacional), conforme disposto na Lei no 13.005 (BRASIL, 2014a). O Programa Internacional de Avaliação de Alunos (PISA) produz indicadores da qualidade do ensino, por meio de testes cognitivos, e compara sistemas educacionais diversos. $O$ exame é realizado a cada três anos por vários países (ORGANIZAÇÃO PARA A COOPERAÇÃO E DESENVOLVIMENTO ECONÔMICO, 2018). O Índice de Desenvolvimento da Educação Básica (IDEB) busca medir a qualidade do ensino nacional e serve para traçar novas metas para as escolas a fim de se equiparar com as médias de países desenvolvidos (BRASIL, 2019).

Porém, os resultados do PISA no ano de 2015 e 2018 revelam que os alunos brasileiros vêm apresentando queda no desempenho das competências avaliadas, conforme resultados divulgados pelo MEC. Foi constatado que muitos alunos chegam ao final da educação básica sem dominar suficientemente as habilidades ligadas ao 
português, matemática e ciências, sendo estas essenciais para que o indivíduo possa exercer a plena cidadania (BRASIL, 2019).

Nesse contexto, o presente estudo busca entender a situação atual do Brasil referente à qualidade de ensino ofertada na educação básica, utilizando como subsídio para a pesquisa os resultados dos indicadores de desempenho e aprendizagem, apresentados nas últimas edições do PISA no ano de 2015 e 2018 e os resultados de 2007 a 2017 do IDEB. O objetivo da pesquisa é confrontar as metas projetadas do PNE, conforme a Lei $n^{\circ}$ 13.005/2014 (BRASIL, 2014a), com os resultados dos indicadores de desempenho internacional, PISA, e nacional, IDEB.

O relatório econômico da Organização para a Cooperação e Desenvolvimento Econômico (2018) ressalta que o Brasil está entre os países com maior taxa de desigualdade social e distribuição de renda do mundo. Moraes (2017) enfatiza que a desigualdade social e a miséria são fatores que dificultam a obtenção de um melhor resultado educacional nos exames do PISA.

A metodologia utilizada neste estudo tem caráter bibliográfico e documental, partindo de fontes secundárias, de cunho bibliográfico, disponibilizadas por sites oficiais, como o MEC, Organização para a Cooperação e Desenvolvimento Econômico (OCDE), Instituto Brasileiro de Geografia e Estatística (IBGE), PNE e projetos de leis online. A apuração de resultados foi embasada em dados disponíveis pelo Instituto Nacional de Estudos e Pesquisas Educacionais Anísio Teixeira (INEP), além de artigos publicados voltados para os indicadores de desempenho da educação básica.

\section{FATORES QUE INFLUENCIAM A EDUCAÇÃO}

O estudo se inicia com abordagem de características peculiares do Brasil, que, de uma forma ou outra, podem ser apontadas como elementos importantes para a construção da trajetória e situação atual da educação. Fatores como diversidade étnica, aspectos históricos, desigualdade social, economia, população, analfabetismo e distribuição de renda estão presentes nos problemas cotidianos e interferem no ensino e aprendizagem ao analisar a conjuntura da educação no país (PREVITALLI; VIEIRA, 2017).

O Ministério da Educação tem o desafio de promover e fiscalizar o ensino de qualidade para toda a população brasileira. O estudo também é baseado na população e na taxa de analfabetismo. Embasado em dados do IBGE (2019b), o Brasil 
é considerado um grande país territorialmente, com $8.515 .767,049 \mathrm{~km}^{2}$, e uma população estimada em 211,7 milhões de habitantes. O faturamento médio do PIB em 2018 foi de 6,8 trilhões, e a renda per capita por pessoa de $\mathrm{R} \$ 1.373,00$ no mesmo ano. O MEC registrou em 2019, cerca de 43,3 milhões de estudantes matriculados na educação básica. Estão inseridas nesse número a educação infantil, o ensino fundamental e médio, conforme dados do Ministério da Educação (INSTITUTO NACIONAL DE ESTUDOS E PESQUISAS EDUCACIONAIS ANÍSIO TEIXEIRA, 2019a).

De acordo com a Pesquisa Nacional por Amostra de Domicílios (PNAD) Contínua realizado pelo IBGE ([2019a]), é tido como analfabeto, quem não sabe escrever, e nem ler um bilhete simples. Sendo assim, em 2018 o Brasil registrou uma taxa de 11,3 milhões de analfabetos, e desse número, os piores índices estão concentrados no estado do Alagoas (17,2\%), Piauí (16,6\%) e Paraíba (16,6\%). Os melhores índices em relação à alfabetização encontram-se nos estados: Rio de Janeiro (2,4\%), Santa Catarina (2,5\%) e São Paulo (2,6\%). Ainda nesse contexto, as pessoas acima de 25 anos que conseguiram terminar a educação básica, somavam $47,4 \%$ em 2018, observe que metade da população considerada adulta não conseguiram obter um diploma em tempo hábil (IBGE, 2019b).

\subsection{Aspectos históricos e seus reflexos na educação contemporânea}

A origem dos costumes herdados pelo povo brasileiro, além da cultura portuguesa, tem grande influência dos nativos indígenas, italianos, alemães, e do povo africano. Em 1822, o Brasil se tornou um país livre e, pela primeira vez, se constituiu uma "cidadania brasileira" fundamentada na monarquia constitucional de base liberal daquela época, que considerava "todos os homens cidadãos livres e iguais" (MATTOS, 2004, p. 7).

Brandão (2007) afirma que a educação de qualidade ao longo da história nunca foi um direito de todos, e sim privilégio das elites, constituindo-se um abismo entre o ensino ministrado nas redes particulares e o ensino ofertado na rede pública. Freire (2014) salienta que a educação brasileira enfrentou muitos obstáculos durante sua trajetória, e, por um longo período, o domínio das elites sobre o governo e seus interesses pessoais, tardaram a criação de políticas eficazes para desenvolvimento da educação como um direito comum. Para esse autor, a educação não deve somente 
superar o analfabetismo, e sim, estimular o pensamento crítico individual, para formação de um cidadão consciente de seu papel, deveres e direitos dentro da sociedade.

Outro aspecto peculiar da educação brasileira é a multiculturalidade presente no sistema educacional, derivado da imigração de diferentes povos que vieram para trabalhar neste território, formando uma diversidade cultural e étnica histórica. Pensando nessa particularidade, as políticas educacionais contemporâneas buscam respeitar e valorizar a pluralidade cultural e social para uma educação igualitária (PREVITALLI; VIEIRA, 2017). Como exemplo, o Plano Nacional de Educação (PNE) vigente até 2024, que estabelece as metas a serem alcançadas pela educação básica. Nessa condição, a meta que busca equidade é a Meta 8 (BRASIL, 2014a, p.11).

\footnotetext{
Meta 8: elevar a escolaridade média da população de 18 (dezoito) a 29 (vinte e nove) anos, de modo a alcançar, no mínimo, 12 (doze) anos de estudo no último ano de vigência deste plano, para as populações do campo, da região de menor escolaridade no País e dos $25 \%$ (vinte e cinco por cento) mais pobres e igualar a escolaridade média entre negros e não negros declarados à Fundação Instituto Brasileiro de Geografia e Estatística - IBGE (BRASIL, 2014a, p. 11).
}

Mattos (2004) ressalta que o fato histórico de os colonizadores portugueses exportarem mão de obra escrava vinda da África, durante o período colonial, caracterizou uma desvalorização e preconceito ao povo afrodescendente. A escravidão do século XVI atrelada ao poder das elites sobre o governo em busca de seus interesses pessoais podem ser apontados como uma das principais razões dos altos índices de desigualdade social e de oportunidades no Brasil, sendo refletidas até os dias atuais.

\subsection{Economia e investimento na educação}

O Relatório econômico da Organização para a Cooperação e Desenvolvimento Econômico (2018) enfatiza que a economia brasileira teve um crescimento considerável nos últimos anos, apesar do desafio constante de controle da inflação, dívida externa e desvalorização do real diante das moedas estrangeiras. Isso sem contar as crises políticas que geram incerteza diante de investidores internacionais. Outro desafio é manter o crescimento inclusivo e a distribuição de renda, de maneira a diminuir a pobreza. 
O Brasil investiu na educação como um todo 6,2\% do PIB de 2015 a 2018. Considera-se um alto investimento quando comparado aos países membros da OCDE, que em média investiram $5,5 \%$ do PIB na educação. "[...] o problema no Brasil, de acordo com o relatório, não está no volume dos gastos, mas na necessidade de aprimoramento de políticas e processos educacionais" (OLIVEIRA, 2018).

Todavia, outros fatores além dos incentivos financeiros, interferem diretamente no desenvolvimento da educação, como: falta de incentivo e acompanhamento familiar na educação dos filhos, fome e miséria, desmotivação dos docentes, dentre outras razões (ORGANIZAÇÃO PARA A COOPERAÇÃO E DESENVOLVIMENTO ECONÔMICO, 2018).

A desigualdade social e a miséria afetam diretamente o desenvolvimento da educação no Brasil, em razão de questões que vão além dos métodos de ensino. Para Medeiros e Oliveira (2014, p. 562), "a redução dessas desigualdades regionais é meta de várias iniciativas políticas", como, por exemplo, o PNE.

Menezes Filho e Oliveira (2014, p. 2), ao pesquisar o período de 2001 a 2009, observou que "a educação contribuiu com cerca de $40 \%$ e $25 \%$ para as quedas dos índices de Gini”. Essa análise é mais uma confirmação da importância da educação para formação de indivíduos preparados para enfrentar as condições adversas da desigualdade social e de oportunidades.

\section{O COMPROMISSO DO BRASIL COM A AGENDA 2030 PARA A EDUCAÇÃO GLOBAL}

A Agenda 2030 foi criada pela ONU em 2015 e tem vigência até 2030, com o objetivo de promover o desenvolvimento sustentável, considerando as diversas esferas que influenciam o homem e a sociedade. Para atingir tal propósito, foram criados 17 Objetivos de Desenvolvimento Sustentável chamados de ODS e 169 metas. Com foco na educação, o presente estudo toma como referência a ODS de $n^{\circ} 4$ da agenda 2030 - "assegurar a educação inclusiva e equitativa e de qualidade, e promover oportunidades de aprendizagem ao longo da vida para todos" (ONU, 2015, p. 18).

O pacto global das Nações Unidas para garantir a educação inclusiva e de qualidade a todos, inspirou a reformulação do PNE no Brasil. Todavia, os investimentos governamentais na educação permanecem enfrentando obstáculos. 
Um exemplo disto é a aprovação da emenda constitucional (EC) n 95/2016, criada pelo governo Michel Temer, que limita os investimentos para as áreas sociais até 2036. Diante desse cenário, a educação brasileira fica em desvantagem para atingir os objetivos propostos pela Agenda 2030 e cumprir as metas do PNE (OGIBA, 2018).

\section{PLANO NACIONAL DE EDUCAÇÃO (PNE) 2014- 2024}

O atual Plano Nacional de Educação foi instituído através da Lei $n^{\circ} 13.005$, de 25 junho de 2014, e tem vigência de 10 anos. Esse plano tem a finalidade de nortear os rumos da educação brasileira e está atrelado ao BNCC (Banco Nacional Comum Curricular), que define as competências e habilidades essenciais à educação básica para o currículo escolar, e, juntos, objetivam a melhoria da qualidade educacional oferecida em todo território nacional (BRASIL, [2014b]).

Analisando o contexto atual do sistema educacional brasileiro, nota-se que 0 MEC, por meio do PNE, traçou metas nacionais, estaduais e municipais para todos os níveis (desde a educação infantil até o ensino superior) da educação, sendo seu objetivo que os alunos da educação básica, alcancem nota 6,0 em proficiência até 2022, conforme a Lei n 13.005/2014 (BRASIL, [2014b]).

Segundo o MEC, a elaboração das diretrizes e metas para o PNE caracteriza um desafio, levando em consideração as desigualdades históricas existentes no Brasil. Desse modo, o foco está em garantir uma educação inclusiva, diminuindo as desigualdades no ensino por região, garantindo a formação para o trabalho e o exercício da cidadania, o respeito à diversidade cultural, a sustentabilidade socioambiental, e "a valorização dos profissionais que atuam na educação de milhares de pessoas todos os dias" (BRASIL, [2014b], p. 9).

No intuito de acompanhar se as metas estão sendo cumpridas, 0 art. $5^{\circ}$ da Lei $n^{\circ}$ 13.005, estabelece que o Instituto Nacional de Estudos e Pesquisas Educacionais Anísio Teixeira (INEP) fica responsável por monitorar, juntamente com o MEC, o aprendizado nas escolas em todo o território nacional, e tornar público os resultados a cada dois anos (BRASIL, 2014a). O resultado é apurado pelo indicador de desempenho de aprendizagem denominado de Índice de Desenvolvimento da Educação Básica (IDEB). 


\subsection{Metas do Plano Nacional de Educação vigente para o Índice de Desenvolvimento da Educação Básica e Programa de Avaliação Internacional de Alunos}

Das metas propostas pelo PNE, o foco para o presente estudo é a meta 7. Sua proposta é melhorar a qualidade do ensino em todas as etapas da educação, considerando o aprendizado e mantendo o fluxo escolar adequado. Para alcançar tal propósito, o PNE projetou metas a serem alcançadas pelo IDEB e PISA, conforme o Quadro 1.

Quadro 1 - Metas nacionais projetadas pelo Plano Nacional de Educação para o Índice de Desenvolvimento da Educação Básica

\begin{tabular}{|c|c|c|c|c|}
\hline IDEB & $\mathbf{2 0 1 5}$ & $\mathbf{2 0 1 7}$ & $\mathbf{2 0 1 9}$ & $\mathbf{2 0 2 1}$ \\
\hline $\begin{array}{c}\text { Anos iniciais do ensino } \\
\text { fundamental }\end{array}$ & 5,2 & 5,5 & 5,7 & 6 \\
\hline $\begin{array}{c}\text { Anos finais do Ensino } \\
\text { fundamental }\end{array}$ & 4,7 & 5 & 5,2 & 5,5 \\
\hline Ensino médio & 4,3 & 4,7 & 5 & 5,2 \\
\hline
\end{tabular}

Fonte: Lei no 13.005 (BRASIL, 2014a).

O Indicador de desempenho de aprendizagem IDEB revela o nível de aprendizagem dos alunos e utiliza a prova Brasil para identificar o domínio dos alunos nas disciplinas de português e matemática, sendo multiplicado pelo fluxo escolar (aprovações, reprovações e abandono). O Inep apura os resultados por rede (pública, privada, federal, estadual, municipal e particular), é separado também por etapa do ensino (anos iniciais, anos finais e ensino médio), percorrendo todos os municípios brasileiros. Dessa forma, apuram-se as médias por unidade federativa e, juntas, formam a média nacional (INSTITUTO NACIONAL DE ESTUDOS E PESQUISAS EDUCACIONAIS ANÍSIO TEIXEIRA, 2018).

Para Horta Neto, Junqueira e Oliveira (2016) as metas projetadas por escola pelo PNE acabam por gerar competição entre instituições e rede de ensino, do mesmo município. O que deveria acontecer é a colaboração entre escolas, no intuito de sanar as dificuldades apresentadas no ensino e aprendizagem. O IDEB deve ser utilizado como suporte para gestão escolar e planejamento do ano letivo ao elaborar o Projeto Político Pedagógico (PPP), pois esse indicador mostra onde a escola deve melhorar. 
Quadro 2 - Metas nacionais projetadas pelo Plano Nacional de Educação para o Programa de Avaliação Internacional de Alunos

\begin{tabular}{|c|c|c|c|}
\hline PISA & 2015 & 2018 & 2021 \\
\hline $\begin{array}{c}\text { Média dos resultados em matemática, } \\
\text { leitura e ciências }\end{array}$ & 438 & 455 & 473 \\
\hline
\end{tabular}

Fonte: Lei $n^{0} 13.005$ (BRASIL, 2014a).

O Quadro 2 expõe a meta 7.11 da Lei no 13.005 (BRASIL, 2014a) "melhorar o desempenho dos alunos da educação básica nas avaliações da aprendizagem no Programa Internacional de Avaliação de Estudantes - PISA, tomado como instrumento externo de referência, internacionalmente reconhecido".

\section{INDICADOR NACIONAL DE QUALIDADE DA EDUCAÇÃO BÁSICA: IDEB}

O Índice de Desenvolvimento da Educação Básica (IDEB), criado em 2007, é um importante indicador de desempenho da educação básica no Brasil. Seus resultados são divulgados a cada 2 anos e ele é utilizado pelo Inep para medir o aprendizado dos alunos nas três etapas de ensino. São elas: anos iniciais e finais do ensino fundamental e ensino médio (INSTITUTO NACIONAL DE ESTUDOS E PESQUISAS EDUCACIONAIS ANÍSIO TEIXEIRA, [2017]).

Para realizar o cálculo do IDEB, o Inep conta com o Sistema Nacional de Avaliação da Educação Básica (SINAEB), instituído pela Lei n 369 de 5 de maio de 2016, que ampliou a atuação de avaliação do Saeb, para todas as etapas e modalidades da educação básica e inclui a avaliação de todos os componentes do ambiente escolar - alunos, gestores, docentes e outros. Esse sistema apura, de forma precisa, através de testes cognitivos, o conhecimento dos alunos em português e matemática, utilizando a prova Brasil. O Inep multiplica a nota obtida no exame com a média do censo escolar e, assim, obtém o IDEB. Essa avaliação é aplicada na rede pública e, também, na rede privada; sendo assim, o Inep obtém uma extensa amostra do ensino ministrado no país (BRASIL, 2016).

O MEC divulga as notas do IDEB de cada escola por meio do Inep. As notas referentes ao desempenho escolar podem ser visualizadas no site Inep, sendo essas informações de extrema importância para os gestores escolares, que as utilizam como suporte ao traçar estratégias para conduzir suas escolas a melhores resultados, 
tornando público a toda a sociedade o rendimento escolar local (INSTITUTO NACIONAL DE ESTUDOS E PESQUISAS EDUCACIONAIS ANÍSIO TEIXEIRA, 2018).

Pode-se visualizar nas Figuras 1 a 3, o resultado do IDEB no período de 10 anos, de 2007 a 2017 (INSTITUTO NACIONAL DE ESTUDOS E PESQUISAS EDUCACIONAIS ANÍSIO TEIXEIRA, 2018). O sistema que abrange a educação básica compreende três níveis: educação infantil, ensino fundamental e ensino médio. A divisão acontece da seguinte forma: do $1^{\circ}$ ao $5^{\circ}$ ano compreende os anos iniciais do ensino fundamental; $6^{\circ}$ ao $9^{\circ}$ ano são chamados de anos finais do ensino fundamental e, por último, o ensino médio, que compreende $01^{\circ}$ ao $3^{\circ}$ ano (INSTITUTO NACIONAL DE ESTUDOS E PESQUISAS EDUCACIONAIS ANÍSIO TEIXEIRA, 2018).

Figura 1 - Notas dos anos iniciais do ensino fundamental comparadas com as metas do Plano Nacional de Educação para o período de 2007 a 2017

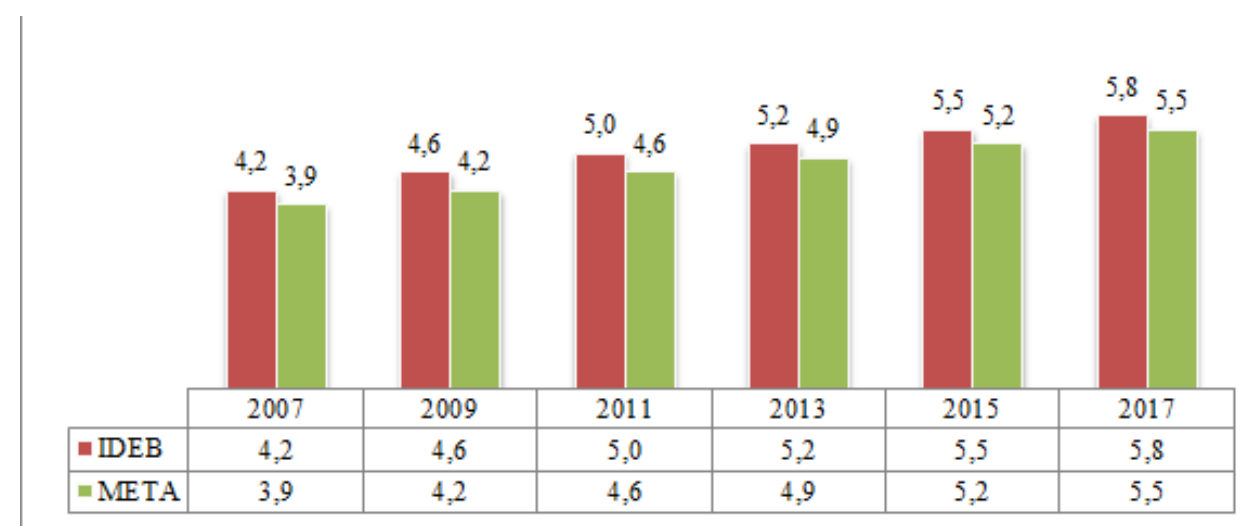

Fonte: Adaptado de Instituto Nacional de Estudos e Pesquisas Educacionais Anísio Teixeira (2018).

A Figura 1 apresenta os dados dos anos iniciais do ensino fundamental. Os resultados expostos são animadores, pois a média geral das escolas de todo território nacional ultrapassou as metas do IDEB, projetado pelo Ministério da Educação. O melhor índice dessa etapa foi alcançado em 2017, com a nota de 5,8 e, se chegar a nota 6,0 , pode ser equiparada à média de países desenvolvidos (INSTITUTO NACIONAL DE ESTUDOS E PESQUISAS EDUCACIONAIS ANÍSIO TEIXEIRA, 2018).

Segundo o Resumo Técnico do IDEB, essa etapa de ensino vem apresentando bons resultados, destaque para oito estados que alcançaram médias igual ou acima de 6 pontos, "são os estado de, Minas Gerais, São Paulo, Espírito 
Santo, Ceará, Paraná, Santa Catarina, Goiás e Distrito Federal" (INSTITUTO NACIONAL DE ESTUDOS E PESQUISAS EDUCACIONAIS ANÍSIO TEIXEIRA, [2017], p. 9). O Ceará, apesar de estar em uma região com grandes desigualdades, apresentou 1,4 pontos acima da meta proposta (meta 4,8, nota obtida 6,2). Os estados do Amapá (meta 4,9, nota obtida 4,6), o Rio de Janeiro (meta 5,9, nota obtida 5,8), e o Rio Grande do Sul (meta 5,9, nota obtida 5,8), não alcançaram a meta para 2017. Ainda assim o resumo geral das médias do $1^{\circ}$ a $5^{\circ}$ obtiveram êxito.

Figura 2 - Notas dos anos finais do ensino fundamental comparadas com as metas do PNE

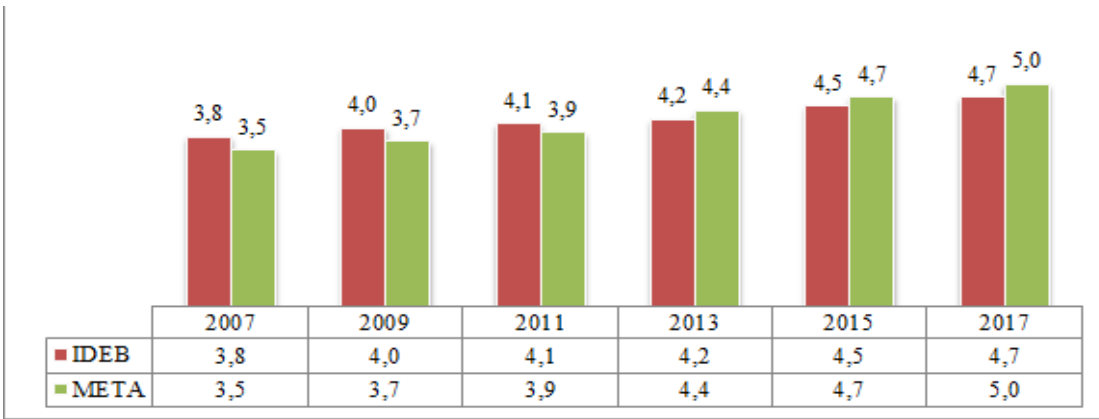

Fonte: Adaptado de Instituto Nacional de Estudos e Pesquisas Educacionais Anísio Teixeira (2018).

Os anos finais do ensino fundamental apresentam bons resultados no IDEB, de 2007 a 2011, como se pode observar na Figura 2. Todavia, de 2013 a 2017, o rendimento escolar diminui e se mantém entre 4,2 e 4,7. Cabe ressaltar que, nessa etapa, é aplicado o Sistema de Avaliação da Educação Básica (SAEB), um importante indicador da educação básica, do $5^{\circ}$ ao $9^{\circ}$ ano. Esse segmento do ensino fundamental é uma transição importante, pois os alunos já começam a pensar em que carreira seguir (INSTITUTO NACIONAL DE ESTUDOS E PESQUISAS EDUCACIONAIS ANÍSIO TEIXEIRA, 2018).

O Resumo Técnico do IDEB (INSTITUTO NACIONAL DE ESTUDOS E PESQUISAS EDUCACIONAIS ANÍSIO TEIXEIRA, [2017], p. 30), enfatiza que, "das 27 unidades da Federação, 23 aumentaram o IDEB, entretanto, apenas 7 (sete) alcançaram a meta proposta para 2017: Rondônia, Amazonas, Ceará, Pernambuco, Alagoas, Mato Grosso e Goiás". A grande surpresa foi o estado de Minas Gerais, com um histórico de excelentes resultados e com melhora do desempenho dos anos finais do ensino fundamental a partir 2013 em diante. 
Figura 3 - Notas do ensino médio comparadas com as metas do PNE

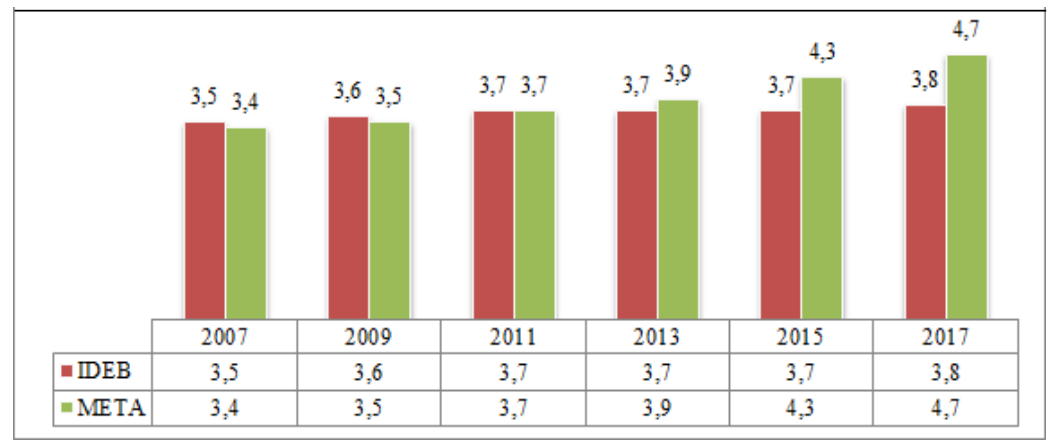

Fonte: Adaptado de Instituto Nacional de Estudos e Pesquisas Educacionais Anísio Teixeira (2018).

Conforme dados do Ministério da Educação (INSTITUTO NACIONAL DE ESTUDOS E PESQUISAS EDUCACIONAIS ANÍSIO TEIXEIRA, [2017]), de todas as etapas da educação básica, os alunos do ensino médio apresentaram os menores índices de desempenho. Observa-se que a nota do ensino médio em 2017, ficou muito abaixo da estimativa feita em 2014 (meta 4,7, nota obtida 3,8).

Apesar do ensino médio alcançar 1 ponto positivo em 2007 e 2009, seu desempenho é preocupante, e nesse contexto salvam-se os estados: Espírito Santo (ES), com a melhor média nacional de 4,4 pontos, Estado do Goiás (GO) com 4,3 e São Paulo (SP) com 4,2. A pior média ficou a cargo do Estado da Bahia (BA), com 3,0 pontos no IDEB de 2017, conforme Resumo Técnico do IDEB (INSTITUTO NACIONAL DE ESTUDOS E PESQUISAS EDUCACIONAIS ANÍSIO TEIXEIRA, [2017]).

O desempenho escolar não caminhou junto dos altos investimentos do governo federal na educação básica. Em 2009, primeiro ano do período de estagnação dos índices, foram gastos $\mathrm{R} \$ 18$ bilhões. Já em 2018, o número saltou para $\mathrm{R} \$ 39$ bilhões, um aumento de 116\% (INSTITUTO NACIONAL DE ESTUDOS E PESQUISAS EDUCACIONAIS ANÍSIO TEIXEIRA, 2019a). O rendimento escolar parece não acompanhar os investimentos e nem as projeções. "Isso evidencia que a correta aplicação dos recursos disponíveis é determinante na gestão escolar" (OLIVEIRA JÚNIOR; MINORI; FROTA, 2019, p. 523). 


\section{INDICADOR INTERNACIONAL DE DESEMPENHO DA EDUCAÇÃO BÁSICA - PISA/OCDE}

O Programa Internacional de Avaliação de Estudantes (PISA), importante indicador de qualidade da educação mundial, foi criado pela Organização para a Cooperação e Desenvolvimento Econômico (OCDE), com o propósito de medir os conhecimentos essenciais adquiridos pelos jovens de 15 anos ao término da educação básica em diferentes países. A última edição do PISA aconteceu no ano de 2018, registrando a participação de 600 mil alunos em 79 países. Esse exame acontece a cada 3 anos e é aplicado pelo Inep (INSTITUTO NACIONAL DE ESTUDOS E PESQUISAS EDUCACIONAIS ANÍSIO TEIXEIRA, 2019b).

Nesse contexto, a OCDE, criada em 1961 na Europa exerce, atualmente, um papel fundamental para a educação global. Conta com 37 países associados, que se reúnem em nome do bem estar social e o fortalecimento das economias, dentre seus membros observa-se economias consolidadas, como os Estados Unidos e economias emergentes como o Chile e México, porém o Brasil ainda não conseguiu atender as exigências para se tornar membro dessa organização (INSTITUTO NACIONAL DE ESTUDOS E PESQUISAS EDUCACIONAIS ANÍSIO TEIXEIRA, 2019b). O motivo da criação do PISA, pode ser entendido como uma forma de medir a qualidade da educação promovida por vários países, na intenção de comparar sistemas educacionais diferentes, e estabelecer um padrão de ensino de alto desempenho (ORGANIZAÇÃO PARA A COOPERAÇÃO E DESENVOLVIMENTO ECONÔMICO, 2016, p. 1).

O convite da OCDE para ingresso do Brasil à organização continua de pé, mas para alcançar tal sonho de equiparar-se aos países desenvolvidos, ainda há um longo caminho a percorrer, começando pela educação. "Portanto, se a educação estivesse no centro da agenda política brasileira, a ela deveriam ser destinados mais recursos, para assim se realizar alternativas mais ousadas de ampliação do acesso e melhorar a qualidade de toda a educação básica" (ABRAHÃO, 2005, p. 856).

\subsection{Resultados do Brasil no PISA nos anos de 2015 e de 2018}

De acordo com o Relatório Brasil no PISA 2018 (INSTITUTO NACIONAL DE ESTUDOS E PESQUISAS EDUCACIONAIS ANÍSIO TEIXEIRA, 2019b, p. 14), este 
se tornou um importante indicador externo de desempenho da educação, visto que apura o nível de proficiência (habilidade em determinada área) dos alunos nos domínios de matemática, literatura e ciências. "O PISA também avalia domínios chamados inovadores, como Letramento Financeiro e Competência Global" (INSTITUTO NACIONAL DE ESTUDOS E PESQUISAS EDUCACIONAIS ANÍSIO TEIXEIRA, 2019b, p. 14). A cada ano um domínio é escolhido como principal; sendo assim, no ano de 2015, o domínio principal foi ciências e, em 2018, literatura. Por meio desse exame, a OCDE equipara os resultados dos países participantes e identifica os melhores sistemas educacionais do mundo, tendo em vista estimular a melhoria da qualidade e equidade do ensino, através de um sistema educacional inclusivo.

Quadro 3 - Resultado das médias das notas dos alunos avaliados pelo PISA 2015 e o de 2018

\begin{tabular}{|c|c|c|c|}
\hline Edição do PISA & $\begin{array}{c}\text { Média das notas } \\
\text { em Matemática }\end{array}$ & $\begin{array}{c}\text { Média das notas } \\
\text { em Ciências }\end{array}$ & $\begin{array}{c}\text { Média das notas } \\
\text { em Literatura }\end{array}$ \\
\hline 2015 & 377 & 401 & 407 \\
\hline 2018 & 384 & 404 & 413 \\
\hline
\end{tabular}

Fonte: Adaptado de Instituto Nacional de Estudos e Pesquisas Educacionais Anísio Teixeira (2019b).

Observa-se, no Quadro 3, que o Brasil apresentou baixo rendimento do exame do PISA, em 2015. A média geral do país ficou em 401 pontos, pois a competência de maior peso era ciências, mas a meta projetada pelo PNE era de 438 pontos. Ainda comparando com a média dos países que pertencem à $\mathrm{OCDE}$, a média apresentada por eles em ciências foi de 493 pontos. Essa média indica sistemas educacionais de alto desempenho. Portanto, a educação brasileira está muito atrás dos países desenvolvidos (ORGANIZAÇÃO PARA A COOPERAÇÃO E DESENVOLVIMENTO ECONÔMICO, 2016).

O relatório Brasil no PISA 2015 (ORGANIZAÇÃO PARA A COOPERAÇÃO E DESENVOLVIMENTO ECONÔMICO, 2016) apresenta os resultados do Brasil nas três competências avaliadas, a saber: matemática 377 pontos, Ciências 401 pontos e literatura 407 pontos. Avaliando o desempenho por federação, o pior resultado foi o do Estado de Alagoas com 360 pontos, e o melhor desempenho ficou a cargo do Espírito Santo com 435 pontos.

O PISA 2018 contou com a participação de 78 países, sendo 36 membros da OCDE e 42 economias parceiras incluindo o Brasil. Nesta edição, o destaque do exame foi literatura. Foram aplicados testes cognitivos e questionários para 10.691 
estudantes, incluindo rede pública e privada das unidades federativas brasileiras, assim como as dependências administrativas federais, municipais, estaduais e privadas, conforme dados do Relatório Brasil no PISA 2018 (INSTITUTO NACIONAL DE ESTUDOS E PESQUISAS EDUCACIONAIS ANÍSIO TEIXEIRA, 2019b).

O Brasil, no PISA de 2018, registrou 413 pontos em literatura, matemática 384 pontos e 404 em ciências. Os melhores resultados são das escolas particulares, que obtiveram 510 pontos e as federais com 503 pontos. Caso se compare somente a rede particular e a federal brasileira, o resultado fica acima da média da OCDE que apresentou as seguintes médias: matemática 489 pontos, ciências 489 pontos e literatura 487. Voltando aos resultados nacionais, observou-se que as escolas municipais alcançaram 330 pontos e as estaduais, 404 pontos, o que, consequentemente, puxou a média nacional para baixo, fechando o geral em 401 pontos (INSTITUTO NACIONAL DE ESTUDOS E PESQUISAS EDUCACIONAIS ANÍSIO TEIXEIRA, 2019b).

O relatório da OCDE referente ao PISA 2018 revelou que os melhores resultados foram apresentados pelos países asiáticos. A China ocupou os três primeiros lugares com o melhor desempenho no exame, com a participação de seus territórios independentes, Hong Kong, Macau, Pequim, Xangai, Jiangsu e Zhejiang, seguidos pela Estônia, Canadá e Finlândia. O Brasil ficou posicionado no ranking de 2018 nas seguintes posições: Literatura $55^{\circ}$, ciências $64^{\circ}$ e matemática $69^{\circ}$, conforme dados divulgados pelo Inep em 2019 (INSTITUTO NACIONAL DE ESTUDOS E PESQUISAS EDUCACIONAIS ANÍSIO TEIXEIRA, 2019b).

\subsection{Desigualdades regionais em alfabetização e o reflexo no PISA}

Segundo Medeiros e Oliveira (2014) os níveis de desigualdade regional e o perfil das famílias em relação à alfabetização afetam diretamente o desempenho escolar e limitam os resultados educacionais, mesmo com a atuação de políticas públicas de convergência regional. As regiões Norte e Nordeste do país apresentam desvantagens em relação ao Sul, Sudeste e Centro-Oeste, em até 1,3 anos de atraso.

Nota-se que o nível de escolaridade dos pais dos alunos interfere diretamente no desenvolvimento e aprendizagem. Segundo o IBGE/Pnad Contínua (IBGE, 2018), o resultado do PISA é um reflexo da escolaridade média da população acima de 25 
anos. Segue a média de anos de estudo por unidade da federação brasileira: região norte 8,7 anos de estudo, região nordeste 7,9 anos de estudo, região sudeste 10 anos de estudo, obteve o melhor índice por região. Na cidade de São Paulo, a população de 18 a 29 anos tem 12,3 anos de estudo em média, tornando-se destaque em todo o Brasil. A região centro-oeste 9,6 anos de estudo e a região sul com 9,5 anos de estudo.

As médias de anos de estudo por região repercutem nas notas do PISA 2018. Veja a seguir as notas obtidas por região, conforme a Tabela 1 elaborada a partir de dados do Relatório Brasil no PISA 2018, fornecidos pelo Inep (INSTITUTO NACIONAL DE ESTUDOS E PESQUISAS EDUCACIONAIS ANÍSIO TEIXEIRA, 2019b):

Tabela 1 - Média Global das notas dos alunos do Brasil e as por suas regiões geográficas na disciplina de literatura por região geográfica do Brasil (PISA 2018)

\begin{tabular}{lr} 
Unid. da Federação & $\begin{array}{c}\text { Média do PISA em } \\
\text { 2018 }\end{array}$ \\
\hline Brasil & 413 \\
\hline Região Norte & 392 \\
\hline Região Nordeste & 389 \\
\hline Região Sudeste & 424 \\
\hline Região Sul & 432 \\
\hline Região Centro-Oeste & 425 \\
\hline
\end{tabular}

Fonte: Adaptado de Instituto Nacional de Estudos e Pesquisas Educacionais Anísio Teixeira (2019b).

A Tabela 1, ilustra o desempenho geral e por região. As melhores notas no PISA estão concentradas no sudeste, centro-oeste e sul, regiões denominadas com melhores índices econômicos e maior concentração de renda e, consequentemente, menor índice de analfabetismo. Como explica o Relatório Brasil no PISA 2018, "embora a média de proficiência do Brasil em letramento em leitura tenha aumentado de 407 em 2015 para 413 em 2018, esses valores não são estatisticamente diferentes quando se consideram os intervalos de confiança" (INSTITUTO NACIONAL DE ESTUDOS E PESQUISAS EDUCACIONAIS ANÍSIO TEIXEIRA, 2019b, p. 64). 


\section{CONSIDERAÇÕES FINAIS}

Este estudo analisou os resultados dos indicadores de desempenho da educação básica no âmbito internacional, representado pelo PISA, e nacional, realizado pelo IDEB. O objetivo da pesquisa foi confrontar as metas projetadas pelo PNE, segundo a Lei $n^{\circ} 13.005$, com os resultados nacionais, a fim de entender a situação da educação básica no Brasil.

De acordo com Pimentel (2019, p. 22) para alcançar as metas propostas pela agenda global para a educação 2030, o principal desafio do Brasil está no "cumprimento do Plano Nacional de Educação e na implementação da Base Nacional Comum Curricular". Embora o progresso tenha sido alcançado no sistema de ensino e aprendizagem dos anos iniciais do ensino fundamental ao longo dos anos, os resultados dos indicadores PISA e IDEB, responsáveis por medir a qualidade da educação básica, são desmotivadores e revelam que o país não consegue alcançar as metas propostas pelo MEC, principalmente quando se analisa a rede pública.

As evidências apontadas neste artigo de revisão indicam que o Brasil está atrasado na alfabetização da massa popular, com 11,3 milhões analfabetos em 2019. Ao analisar os gráficos, tabelas e quadros, observou-se que a maior dificuldade apresentada pelos alunos está nas etapas dos anos finais do ensino fundamental e ensino médio com baixos índices de aprendizagem.

Nesse contexto, Mattos (2004) diz que a educação brasileira se tornou um reflexo de sua herança histórica e do desenvolvimento tardio das políticas públicas voltadas para equidade de um sistema educativo como um bem público. Já Young (2016, p. 14) enfatiza que "não é justo nem equitativo quando um conhecimento de baixa qualidade é oferecido às crianças, o que não as leva para além das próprias experiências", apresentando-se em desvantagem ao competir por melhores vagas de emprego no futuro.

Por fim, conclui-se que a melhoria do ensino não está ligada somente aos investimentos financeiros, pois de acordo com o estudo apresentado, o Brasil investiu 6,2\% do PIB na educação de 2015 a 2018, taxa superior à média de investimentos dos países da OCDE. O desempenho educacional é influenciado por fatores que vão além da sala de aula, como por exemplo, o desvio de verbas escolares, violência, má distribuição de renda, desmotivação dos docentes, falta de acompanhamento familiar, fome e miséria, além do grau de instrução dos pais. Observa-se a necessidade de 
aprimoramento das políticas e processos educacionais para o setor público, buscando nivelar a aprendizagem do ensino das elites e dos mais vulneráveis.

\section{REFERÊNCIAS}

ABRAHÃO, J. Financiamento e gasto público da educação básica no Brasil e comparações com alguns países da OCDE e América Latina. Educação \& Sociedade, Campinas, v. 26, n. 92, p. 841-858, out. 2005. Disponível em: https://www.scielo.br/pdf/es/v26n92/v26n92a07.pdf. Acesso em: 22 jun. 2020.

AKKARI, A. A agenda internacional para educação 2030: consenso "frágil" ou instrumento de mobilização dos atores da educação no século XXI? Revista Diálogo Educacional, Curitiba, v. 17, n. 53, p. 937-958, 2017. Disponível em: https://periodicos.pucpr.br/index.php/dialogoeducacional/article/view/8495. Acesso em: 22 jun. 2020.

BRANDÃO, C. R. O que é educação. São Paulo: Editora Brasiliense, 2007. (Coleção primeiros passos).

BRASIL. Lei no 13.005, de 25 de junho de 2014. Aprova o Plano Nacional de Educação - PNE e dá outras providências. Brasilia, DF: Presidência da República, 2014a. Disponível em: http://www.planalto.gov.br/ccivil_03/_ato20112014/2014/lei/l13005.htm. Acesso em: 14 de jul. 2020.

BRASIL. Ministério da Educação. PNE: Plano Nacional de Educação. PND: em movimento, [2014b]. Disponível em: http://pne.mec.gov.br/. Acesso em: 21 nov. 2019.

BRASIL. Ministério da Educação. Pisa 2018 revela baixo desempenho escolar em Leitura, Matemática e Ciências no Brasil. Portal do MEC, [S.I.], 3 de dezembro de 2019. Disponível em: http://portal.mec.gov.br/busca-geral/211noticias/218175739/83191-pisa-2018-revela-baixo-desempenho-escolar-em-leituramatematica-e-ciencias-no-brasil. Acesso em: 14 jul. de 2020.

BRASIL. Portaria $n^{\circ}$. 369, de 5 de maio de 2016. Institui o Sistema Nacional de Avaliação da Educação Básica - Sinaeb. Diário Oficial da União, sessão 1, edição extra: Brasília, DF, 6 mai. 2016. Disponível em: https://www.in.gov.br/materia//asset_publisher/Kujrw0TZC2Mb/content/id/22793545/do1-2016-05-06-portaria-no369-de-5-de-maio-de-2016-22793435. Acesso em: 21 nov. 2019.

INSTITUTO NACIONAL DE ESTUDOS E PESQUISAS EDUCACIONAIS ANÍSIO TEIXEIRA. Resumo Técnico: resultados do índice de desenvolvimento da educação básica. [S.I.]: INEP, [2017]. Disponível em:

http://download.inep.gov.br/educacao_basica/portal_ideb/planilhas_para_download/2 017/ResumoTecnico_Ideb_2005-2017.pdf. Acesso em: 15 de jul. 2020. TEIXEIRA. Resumo Técnico IDEB 2005-2017. [S.I.]: INEP, 2018. Disponível em: 
http://download.inep.gov.br/educacao_basica/portal_IDEB/planilhas_para_download/ 2017/Resumo Técnico IDEB 2005-2017.pdf. Acesso em: 20 jan. 2020.

INSTITUTO NACIONAL DE ESTUDOS E PESQUISAS EDUCACIONAIS ANÍSIO TEIXEIRA. Metas e projeções. 2019a. Disponível em:

http://download.inep.gov.br/educacao_basica/portal_IDEB/o_que_sao_as_metas/Arti go_projeções.pdf. Acesso em: 15 jan. 2020.

INSTITUTO NACIONAL DE ESTUDOS E PESQUISAS EDUCACIONAIS ANÍSIO TEIXEIRA. 2019a. Relatório Brasil no PISA 2018: Versão Preliminar. INEP: Brasília, DF, 2019b. Disponível em:

http://download.inep.gov.br/acoes_internacionais/pisa/documentos/2019/relatórioPIS A2018preliminar.pdf/. Acesso em: 14 jul. 2020.

FREIRE, P. Educação como prática da liberdade. 1 ed. São Paulo: Editora Paz e Terra, 2014. E-book.

IBGE. PNAD contínua: pesquisa nacional por amostra contínua: Educação. IBGE, [S.I.], 2018. Disponível em:

https://agenciadenoticias.ibge.gov.br/media/com_mediaibge/arquivos/00e02 a8bb67cdedc4fb22601ed264c00.pdf. Acesso em: 05 ago. 2020.

IBGE. Educação. IBGEeduca, [S.I.], [2019a]. Disponível em:

https://educa.ibge.gov.br/jovens/conheça-o-brasil/populacao/18317-educacao.html. Acesso em: 11 abr. 2020.

IBGE. PNAD Contínua 2018: 10\% da população concentram 43,1\% da massa de rendimentos do país. Agência IBGE Notícias, 17 de outubro de 2019b. Disponível em: https://agenciadenoticias.ibge.gov.br/agencia-sala-de-imprensa/2013-agenciade-noticias/releases/25700-pnad-contiua-2018-10-da-populacao-concentram-43-1da-massa-de-rendimentos-do-pais. Acesso em: 20 abr. 2020.

MATTOS, H. M. Escravidão e Cidadania no Brasil Monárquico. 2. ed. Rio de Janeiro: Jorge Zahar, 2004. p. 1-63. E-book.

MEDEIROS, M.; OLIVEIRA, L. F. B. de. Desigualdades regionais em educação: potencial de convergência. Sociedade e Estado, [S.I.], v. 29, n. 2, p. 561-585, mai./ago. 2014. Disponível em: https://www.scielo.br/scielo.php?pid=S010269922014000200012\&script=sci_abstract\&tIng=pt. Acesso em: 20 abr. 2020.

MENEZES FILHO, N.; OLIVEIRA, A. P. A Contribuição da Educação para a Queda da Desigualdade de Renda percapta no Brasil. Policy Paper, n. 9, jan. 2014.

Disponível em: https://www.insper.edu.br/wpcontent/uploads/2018/09/PolicyPaper_Educacao_Desigualdade.pdf. Acesso em: 20 abr. 2020.

MORAES, C. S. V. O ensino médio e as comparações internacionais: Brasil, Inglaterra e Finlândia. Educação \& Sociedade, Campinas, v. 38, n. 139, p. 405-429, abr./jun. 2017. Disponível em: https://www.scielo.br/pdf/es/v38n139/1678-4626-es38-139-00405.pdf. Acesso em: 20 abr. 2020. 
NETO, J. L. H.; JUNQUEIRA, R. D.; OLIVEIRA, A. S. de. Do Saeb ao Sinaeb: prolongamentos críticos da avaliação da educação básica. Em Aberto, Brasília, v. 29, n. 96, p. 21-37, mai./ago. 2016. Disponível em:

http://rbep.inep.gov.br/ojs3/index.php/emaberto/article/view/3149. Acesso em: 20 abr. 2020.

OGIBA, S. M. M (org.). Garantia do Direito à Educação: monitorando o PNE-Lei no 13.005/2014. Porto Alegre: Editora UFRGS, 2018. p. 1-154. Disponível em: https://lume.ufrgs.br/handle/10183/182257. Acesso em: 5 de ago. 2020.

OLIVEIRA JÚNIOR, M. C. de; MINORI, A. M.; FROTA, M. S. Recursos destinados à educação e resultados alcançados no ldeb de uma capital brasileira. Cadernos EBAPE. BR, Rio de Janeiro, v. 17, n. 3, p. 523-538, jun./set. 2019. Disponível em: https://www.scielo.br/scielo.php?script=sci_abstract\&pid=S1679-

39512019000300523\&lng=en\&nrm=iso\&tlng=pt. Acesso em: 6 de ago. 2020.

OLIVEIRA, K. Brasil gasta $6 \%$ do PIB na educação, mas desempenho escolar continua ruim. Agência Brasil, Brasília, 6 de julho de 2018. Disponível em: https://agenciabrasil.ebc.com.br/educacao/noticia/2018-07/brasil-gasta-6-do-pib-emeducacao-mas-desempenho-escolar-e-ruim\#. Acesso em: 22 jun. 2020.

ONU. Transformando Nosso Mundo: a Agenda 2030 para o Desenvolvimento Sustentável. 2015. Disponível em: https://nacoesunidas.org/ wp-content/uploads/2015/10/agenda2030-pt-br.pdf. Acesso em: 10 ago. 2020.

ORGANIZAÇÃO PARA A COOPERAÇÃO E DESENVOLVIMENTO ECONÔMICO. Brasil no PISA 2015: Análises e reflexões sobre o desempenho dos estudantes brasileiros. São Paulo: Fundação Santillana, 2016. Disponível em: http://download.inep.gov.br/acoes_internacionais/pisa/resultados/2015/pisa2 015_completo_final_baixa.pdf. Acesso em: 20 jul. 2020.

ORGANIZAÇÃO PARA A COOPERAÇÃO E DESENVOLVIMENTO ECONÔMICO. Programme for international student assessment (Pisa) results from Pisa 2015: Brasil. OCDE: [S.I.], 2016. Disponível em: https://www.oecd.org/pisa/PISA-2015Brazil-PRT.pdf. Acesso em: 5 de ago. 2020.

ORGANIZAÇÃO PARA A COOPERAÇÃO E DESENVOLVIMENTO ECONÔMICO. Relatório Econômico OCDE: Brasil fevereiro 2018: resumo. In: ORGANIZAÇÃO PARA A COOPERAÇÃO E DESENVOLVIMENTO ECONÔMICO. Relatórios Econômicos da OCDE: Brasil 2018. OCDE: [S.I.], 2017. Disponível em: http://www.oecd.org/economy/surveys/Br azil-2018-OECD-economic-survey-overview-Portuguese.pdf. Acesso em: 19 de jan. 2020.

PIMENTEL, G. S. R. O Brasil e os desafios da educação e dos educadores na agenda 2030 da ONU. Revista Nova Paideia: revista Interdisciplinar em Educação e Pesquisa, Brasília, DF, v. 1, n. 3, p. 22-33, 2019. 
PREVITALLI, I. M.; VIEIRA, H. E. S. Educação e Diversidade. Londrina: Editora e Distribuidora Educacional, 2017.

YOUNG, M. F. D. Por que o conhecimento é importante para as escolas do século XXI? Cadernos de Pesquisa, [S.I.], v. 46, n. 159, p. 18-37, jan./mar. 2016.

Disponível em: https://www.scielo.br/pdf/cp/v46n159/1980-5314-cp-46-15900018.pdf. Acesso em: 10 ago. 2020. 